\title{
Teaching groupwork at a distance using an asynchronous online role-play
}

\author{
Joanne Levine ${ }^{1}$
}

\begin{abstract}
Given the proliferation of online groups and growth in distance learning, there is a pressing need to develop best practices for teaching group work online. The following paper explores the implementation of an asynchronous role-play exercise conducted in online undergraduate classes about group work. The overall purposes were to help students learn about group stages and dynamics through participating in an experiential exercise and further develop their knowledge about online groups. Thematic analyses of students' reflections on their online role-play experience are discussed, considerations regarding the complex role of the instructor are explored, educational benefits and related challenges are analyzed, and guidelines are presented to facilitate best practices when implementing an online role-play exercise.
\end{abstract}

Keywords: distance learning; online role-play; groupwork; experiential learning; human service education

1. Assistant Professor and Academic Area Coordinator, Human Services

Address for correspondence: State University of New York - Empire State College, Center for Distance Learning, 113 West Ave, Saratoga Springs, NY 12866, USA. Joanne.Levine@esc.edu

Date of first (online) publication: 


\section{Introduction}

The current mental health and educational landscapes are colored by helping professionals, mental health consumers, and students actively engaged in online activity. Distance learning and support groups are flourishing. For example, on Yahoo alone there are almost 9,000 listings in the health and wellness group area spanning a wide range of conditions from the common to the obscure. Examples include online support groups for children of hoarders, individuals with schizophrenia, hydrocephalus, borderline personality disorder, and mitochondrial disease. Of further note, is that thousands of people participate.

Online support groups also available through highly respected organizations including Cancer Care, Alzheimer's Association, and Alcoholics Anonymous. Mental health professionals addressing the needs of those suffering with a particular disease as well as their caregivers moderate many of these groups using discussion forums, email, and chat.

In the educational arena, online learning continues to evolve; twothirds (66 percent) of 2-year and 4-year degree granting postsecondary institutions in the United States offer online, hybrid/blended online, or other distance education courses (Parab \& Lewis, 2008) and about 4.3 million undergraduate students, or 20 percent of all undergraduates, have taken at least one distance education course (U.S. Department of Education, 2011). Programs in human services, counseling, and social work are also increasing their online course offerings.

Given the proliferation of online groups and growth in distance learning, there is a need to discuss current efforts using these modalities to teach groupwork. Yet, there is a dearth of literature on this topic. In the following, one effort will be discussed; the implementation of an asynchronous role-play in an online undergraduate class about groupwork. While the overall purpose was to provide students with an experiential exercise about group stages and dynamics, participation in this exercise also provided an opportunity to develop a comfort level and familiarity with online groups. Thematic analyses of students' reflections on their online role-play experience help inform this discussion and suggest a framework for its implementation. 


\section{Historical and theoretical foundations of role-play}

Role-play is derived from the work of Jacob Levy Moreno MD who developed psychodrama as a group psychotherapy technique (http:// www.asgpp.org). Psychodrama conducted under the supervision of a therapist is used as one of the adjunct therapies for treating trauma disorders. In therapeutic settings, participants reenact life situations or feelings with a goal of gaining insight or learning new ways of coping. This guided dramatic action is used either by an individual or group (sociodrama) to examine problems or issues. In a classically structured psychodrama, there are three distinct phases (structural components) of group interaction (http://www.asgpp.org/):

- The warm up: the group theme is selected and a protagonist is identified

- The action: the problem is dramatized and the protagonist explores new methods of resolving it.

- The sharing: group members are invited to express their connection with the protagonist's work.

Role-play is used in a wide range of educational settings because it is an experiential and interactive teaching method enabling students to rehearse situations in preparation for a future performance and improve their abilities within a role; for example, occupational roleplays, educational role-play exercises, and certain military war games (Rochelle, 2010).

Piaget's classical theory of learning provides a theoretical foundation for role-play as an experiential learning tool. Learning theory describes accommodation and assimilation as cognitive processes that facilitate acquiring new information and behaviors (Reinking et al, 2002). Piaget described assimilation as when 'complex but familiar external objects are simplified to fill pre-existent categories in your head' and accommodation as 'having to change the ideas in your head to fit the realities of external objects (Atherton, 2010).' Accommodation and assimilation are complementary and concurrent, both enabling an internalization of the outside world. Psychodrama and role- play both challenge participants to modify their preexisting conceptions and behaviors. This feedback encourages learning new behaviors and 
provides fresh insights which "change their mental map or alter it to fit their new perceptions ... this tends to be the type of learning that is skill based and hard to forget (Blater, 2009).'

\section{Virtual environments and online role-playing}

Thousands of people daily engage in recreational role-plays through online gaming but increasingly online role-plays are being used for educational purposes. Online role-play is an experiential and interactive format. Proficiency is attained by an inquiry-based collaborative interaction with other learners; teachers participate as co-learners and act as facilitators. Learning emerges through interactions with other students via the technology that mediates students' interactions either synchronously or asynchronously (Nelson \& Blenkin, 2007).

Two widely used virtual environments where online role-play occurs are Massively Multiplayer Online Role-Plays (MMORPG) which evolved out of Multi-Use Dungeons (MUDs); multiplayer computer role- playing games. MMORPGs are highly graphical 2 or $3 \mathrm{D}$ videogames played online, on game consoles, and increasingly on mobile devices (see Table 1). Avatars (self-created digital characters) can interact with the gaming software and other avatars. Avatars and their environments are highly customized by the players and this real life simulation allows opportunities for collaboration and interaction (Childress \& Braswell, 2006; Yee, 2006).

Interaction and communication occur both asynchronously and synchronously (in real time) through text- based mediums, typically email and discussion boards, among a network of people without constraints of time and place (Mayadas, 1997; Jones 2007). Increasingly, communication through broadband connections (such as a cable modem) to the game manufacturer's server (for example, Microsoft and Xbox Live) enables players to speak with each other in real time during role-playing sessions.

MMORGs also provide educators with opportunities for developing learning activities that closely replicate 'real world' experiences. Second Life, for example, is the most widely used MMORPG in educational settings. There is a wiki (a website that all users can contribute to and edit) devoted specifically to how this virtual world can be used for

Groupwork Vol. 23(1), 2013, pp.56-72. DOI: 10.1921/1601230104 


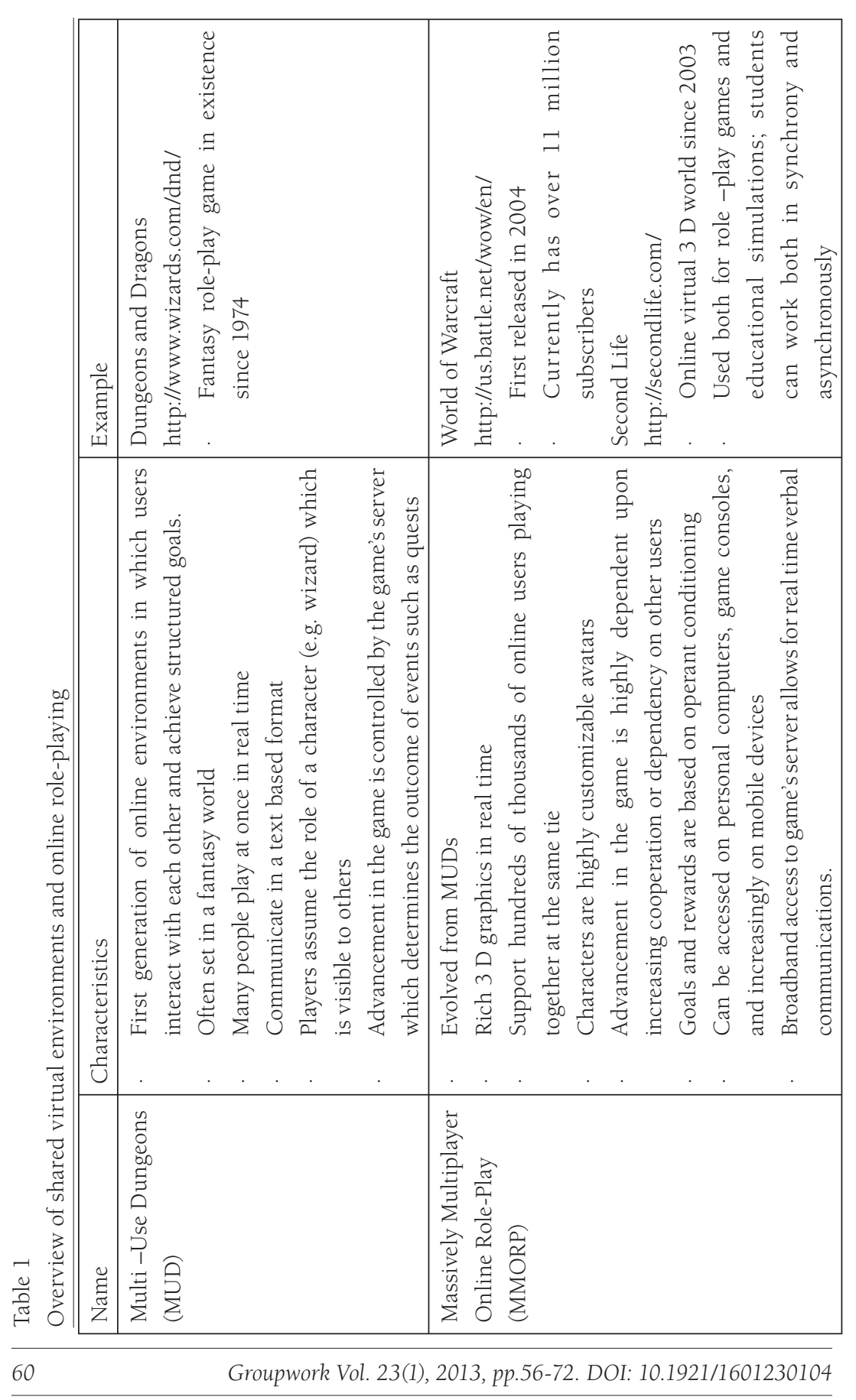


Teaching groupwork at a distance using an asynchronous online role-play

such endeavors (see: http://wiki.secondlife.com/wiki/Second_Life_ Education/Resources). This wiki includes links to sites providing training in Second Life, videos showcasing educators, and direct links to a sampling of the several hundred educational institutions with virtual campuses. Examples of educational institutions with virtual worlds in Second Life include Hong Kong Polytechnic University, School of Hotel and Tourism Management, the Virtual University of Edinburgh, and The U.S. Centers for Disease Control and Prevention (CDC).

\section{The online role-play exercise}

Participants in this role-play were undergraduate students enrolled in a human services program at a large state university located in the northeastern United States. The groupwork course was offered completely online with the intent of enabling students to plan, execute, and evaluate basic counseling groups. Course content also included the principles and ethics involved in psychotherapeutic groups. An outcome of successful course completion was developing need skills making it possible to lead groups if called upon by more highly trained professional staff.

Preparation for the role-play included the course instructor randomly placing students into smaller groups for the duration of this sixweek exercise. Due to insurmountable barriers arising from many differing time zones and schedules, the role- play was conducted in an asynchronous format through written dialogue posted in discussion boards. These were located in course modules and only visible to the course instructor and students. The online course was delivered using Angel, a software management program for online learning.

The topic for the role-play was a peer supervision group. Students were asked to discuss a group experience with clients in their current workplace or volunteer group or, if they were not currently involved in groupwork, from one of the case studies provided in the course (see below). Students were required to do the preliminary planning for the group right down to practical issues such as where and when the group would meet, goals and objectives for the group, an outline of the initial session, and some of the problems they expected to encounter.

Students choosing the case study option assumed characters which

Groupwork Vol. 23(1), 2013, pp.56-72. DOI: 10.1921/1601230104 
were provided in the course. Efforts were made for 'gender ambivalence' so that any student could play them. Students were encouraged to elaborate on group members, their problems, and issues faced in running these groups. Examples of characters and case studies used in the role-play are as follows:

Pat: You are 42 years old, married, and parent to two teenagers. You work part time in an afternoon program for children ages 8 to 12. You have recently been asked to run a small group for six children whose parents have recently gone through a divorce. There are three boys and three girls. For the most part the divorces have been amicable, but two of the children (from different families) have been involved in bitter custody disputes. You have known all the children in your role as a recreational supervisor, but this is the first time you have ever dealt with anything serious.

Sam/Samantha: You are 30 years old and a veteran. You are working as a physical therapy aid in a VA hospital with many wounded soldiers returning from the Iraq war. All of your patients have lost major body parts in the war and/or are unable to walk. Most are depressed. Some have post-traumatic stress disorder. You have been asked to run a group of from six to eight patients that will prepare these young men and women for their return to civilian life. As you role- play, tell the group about the soldiers you have chosen for the group, the problems they face, and why you have chosen them.

'Hank' (Henrietta or Henry): You are 50 years old and are one of the brave few who have been working as a Family/Youth Services Caseworker for your whole career. Recently, you have asked your supervisor to let you try a 'Parents' Anonymous' type group as a way of working with abusive parents. You have in mind that you will work with 8 to 10 parents with children ranging in age from babies to young teens. You would like to work with couples (including intact families, step-families, and families where unmarried adults are living together) but are unsure if this will be possible. As you role-play, tell the group about the clients you have chosen.

Students participated in the online role-play through structured discussions related to stages in group development. These were supplemented by course readings and a DVD showing experienced group therapists working with clients. Examples of discussion questions are provided below. 
Identify some of your feelings about joining a Peer Supervision group. What are your expectations of the group and the group members? How are the dynamics in Peer Supervision groups different from therapeutic groups, such as the course project groups?

What specific characteristics might you expect at the ending stage of your group's development (the group you are leading on your own) that differs from the working stage?

At the ending phase of your course project group, what three leadership skills do you see as being extremely important? Which of these skills are strong areas for you? Which skills need improvement? What are the main challenges you expect to face at this stage in your group's development?

\section{Instructor's presence in the online role-play}

There is debate about the role of instructor presence in asynchronous online discussion threads. On one hand, a clear instructor presence is needed to ensure higher levels of learning and frequent assessments of individual progress in the class. On the other hand, discussion threads are an opportunity for well-informed instructors to scaffold learning as a participant. They do so by posing Socratic probing questions rather than posting as an authority on the topic being discussed (Bangert, 2008).

Recent investigation on the benefits of instructor presence in discussions identified this as one of the ways to facilitate students' learning (Diamond, 1999; Shea, Hayes \& Vickers, 2010). It was also suggested that the totality of instructors' communications, for example, email, course announcements, feedback on assignments, comprise teaching presence which is an indicator of online instructional quality. Empirical research has supported this view with evidence indicating strong correlations between the quality of teaching presence and student satisfaction and learning (Bangert, 2008; Picciano, 2002; Shea, Pickett, $\&$ Pelz, 2003).

However, in an online role-play the issue of instructors' presence is complicated because they must assume a 'dual role.' An instructor enters the role-play as a character, the mental health team coordinator,

Groupwork Vol. 23(1), 2013, pp.56-72. DOI: 10.1921/1601230104 
but is not charged with formally leading the peer supervision sessions. As the mental health team coordinator, primary functions are to provide structural support (for example, addressing technical issues) and comments on students' postings about their groups (for example, Sam/Samantha's Parents Anonymous Group). They also intervene as the course instructor: facilitating interactions and discussions, relating the discussion to course content, ensuring communication is appropriate (for example, not posting rude or personally attacking comments), answering questions, and providing formal feedback on students' participation in the role- play. Examples from instructors' comments below illustrate their participation in the role-play from the perspective of course instructor or the team mental health coordinator.

I am glad to see the discussion interaction going well. I encourage everyone to print out the initial posting in the last module that your group members posted describing their group. It will be helpful when giving feedback and applying concepts. In this online setting, what actions on the part of the instructor or fellow students encourage you to participate? What inhibits your participation (other than such practical considerations as lack of time)? (An example of discussion posting as the course instructor)

Angry outbursts and conflict can be uncomfortable, but need to be addressed. I have witnessed people have angry outbursts when confronted, deny and then go through drug tests that either come up positive or negative, and have also witnessed people admit it and therefore have a second chance at treatment.(an example of discussion posting as the team coordinator)

What are some of the group ideas on personal display of emotion from the leader? How much is too much? (An example of discussion posting as the course instructor)

The focus is the client; we are there for the emotional/therapeutic benefit of the client. Is the emotion we are sharing going to benefit the client, or does sharing it benefit us at the time? That is a good question to ask ourselves. We need to be able to maintain control over our emotions, yet still be human. Sometimes, body language or a few simple words such as, 'What you said really touched me....Did anyone else have the same reaction (this puts the focus back on the group)?' (An example of discussion posting as the course instructor) 


\section{Students' reflections on their experience in the role-play}

The final assignment asked students to engage in self-reflection about their role-play experience. Content analysis of essays from one hundred students over three semesters elicited the following five themes (from most to least frequent). These themes are presented below with representative student comments.

Theme 1: Participating in the online role-play increased students' self-awareness about their behavior in groups.

I know that even if group members aren't looking at me as someone who can help them, they are still watching every move I make and that I need to be aware of what I say, how I say it, and what my body language is putting off. I also have learned that I have fears about leading a group and what may happen though I now know how to deal with those fears and how to handle those situations, such as conflict in a group.

This course has also given me some insight into my own behavior in a group. I have learned from some of my fellow students how to respond appropriately and sometimes I have witnessed responses I would not want to emulate.

I have to admit that this group process made me realize that some people deal with issues I would never consider as challenging as they do, but it is not up to me to decide what others should fear.

It's interesting because throughout the course I focused a lot on the responsibilities and functions of a leader, and in doing so I identified a few things I could improve about myself.

Theme 2: Participation in the online role-play increased students' knowledge about group dynamics and development.

The process of online group has provided me with relevant information concerning the characteristics of group dynamics, collaboration with individuals I agree with, disagree with, or have no idea what they are talking about... which I can build upon with practical experience enabling me to conduct a group session successfully.

Groupwork Vol. 23(1), 2013, pp.56-72. DOI: 10.1921/1601230104 
Joanne Levine

The peer supervision group was a great place to receive feedback and support.

I have learned how to start, maintain, facilitate and successfully end a group. I am very happy with the knowledge I have gained.'

'I really did enjoy this class and learned so much on group practice stages and ideas. I have held small meetings with clients but nothing close to this role-play

I found the activities and assignments in this course to be very helpful, especially the peer group (online role-play) supervision.

The online group I participated in went better than I had expected it to. Everyone participated a lot and their feedback was both helpful and informative.

Theme 3: Being able to observe experienced group therapists at work through viewing a DVD and online videos enriched the learning experience.

... gave me the opportunity to see, first hand, how professional therapists perform under certain situations

Watching the DVD helped me to understand how brave it is to share meaningful aspects of self and important that sharing is in the growth of self but also of others

I also enjoyed using the DVD to compare to the text information

The text was interesting but the DVD was essential; to actually see a group in progress (especially as I have no experience in groupwork) pulled everything together. It is one thing to read a text and imagine group dynamics, but it's another to view it in action.

Theme 4: Some students experienced anxiety about participating in the online role-play but had their feelings normalized by other students in the class.

I honestly did not know what to expect when I came into this course. I did feel that having simultaneous discussions became somewhat stressful, but each discussion was also very meaningful.

When I began taking this course I wondered what it would be like to learn about 
Teaching groupwork at a distance using an asynchronous online role-play

group work in the context of an online course. Soon after, this became my most interesting and favorite course.

\section{Theme 5: Face-to-face contact would have enhanced this learning experience.}

Overall, it was as close as an online class get without being face to face interaction. The only thing that would have been better would have been groups that met at certain times via video camera and had sessions like that. It is a difficult task to achieve due to everyone's schedules, etc., but maybe just once a week for an hour to start. That is the only way I can think of that this course could have been improved.

I enjoyed this class with one exception. I felt this type of class would be more productive and have a more lasting impact if we were in a classroom or in a setting where we could see each other and physically interact with each other. Face to face encounters are more rewarding than a conversation on a computer.

One thing I would have liked out of this course is if it were perhaps offered as a residency. This would allow people to meet face to face and to even hold a group and enable the students to exercise the skills that they obtained from the course. It is easy to say that you did something effectively but it is something greater to have that validated by your peers.

\section{Benefits of the online role-play experience}

The asynchronous format enabled online students to participate in an experiential exercise that may not have been possible otherwise given their varying schedules and time zones. This format also facilitated learning in several ways. Firstly, the asynchronicity and text-based communications enabled time for students to process and self - reflect about discussion topics and postings. Secondly, instructors were able to monitor the role-play discussions to ensure appropriate interactions and participation by all students enrolled in the course. Thirdly, participants were able to safely challenge stereotypes, explore, and experiment with responses reflective of new information. Finally, written communications remain available for the duration of the entire course, not just for one class period or semester. They could be printed

Groupwork Vol. 23(1), 2013, pp.56-72. DOI: 10.1921/1601230104 
out and made available beyond the life of the course.

Additional benefits were apparent from students' comments where they expressed opinions that the online role-play helped increase selfawareness about their behavior in groups while learning about group processes and dynamics. It seemed apparent from their comments that some benefited from support group participation such as insights about their social interactions based on feedback from others in the group. For others, this experience provided motivation to continue developing groupwork skills so they could competently offer this modality to clients.

\section{Challenges in the online role-play}

As identified in themes above, a primary challenge arose from the asynchronous online format which did not allow students to have verbal and non-verbal (for example, body language) interactions. Students' presentations of self were conveyed through their written comments and papers. This provided the instructor with one form of observation because students' emotional tone and understanding of course content was conveyed through their writings. A related challenge was creating opportunities for students to observe experienced group therapists in action. This was addressed by having them view a DVD which came with their textbook and supplemented with links to relevant online videos. These were viewed by everyone in the class providing a common frame of reference for discussions. As technology and distance learning evolve, it will be possible to integrate webcams and other modalities providing face time to help students and instructors view each other. However, using face time technology requires synchronous communication which is problematic for students and instructors living in different time zones.

Another challenge arose in providing enough structure and information so students could assume a role and enact the 'play.' This was addressed by having specific course content providing information on the topic for the role-play, the duration, and expectations for participation by students and the instructor. For example, as this was a role-play about a peer supervision group, students were informed the instructor would not take a leadership role in the discussion; he or 
she would assume the character of team coordinator. Yet, as discussed earlier, it is not possible to completely divorce the instructor from their pedagogical duties. The major challenge for instructors was to be as unobtrusive as possible while ensuring that students enacted their roles, feedback was provided, and the structure of the class was maintained.

\section{Suggested guidelines and conclusion}

Suggested guidelines for implementing this type of experiential online exercise are as follows. These guidelines are derived from the thematic content discussed earlier and experience with this exercise over several semesters.

1. Decide whether the role-play will be asynchronous or synchronous. This should be based upon considerations such the time zones and schedules of students and instructors. A course poll or discussion board can be instituted and relevant information obtained.

2. Allow ample time for students' preparation: it suggested that roleplay be introduced, at the minimum, after exposure to course content about initial phases in group development and dynamics. Students can then begin to enact the role-play with information which enables them to provide substantive comments.

3. Students who enter the role-play using a 'real life' group must be instructed not to use identifying information about group members. They also should not self-disclose personal information about their prior history (for example, substance abuse, domestic violence) as this is a role-play in a course and not an actual therapy group.

4. Prior to the role-play, students should be prepared in discussion forums where they can have their questions answered about the mechanics of the role-play for example, duration) and discuss any concerns they may have. Having others in the class share their concerns can help normalize any anxiety about embarking on the role-play.

5. Provide the class with a clear description of what the role-play will be about, the duration, and detailed descriptions of the roles/ characters. 
6. Provide clarity about the dual roles the instructor will hold. As discussed above, the instructor will have a character to play (Team Mental Health Coordinator) while continuing to instruct the course and provide formal feedback.

7. Clearly define expectations about participation in the role -play including the frequency of postings and the need to provide substantive postings reflective of course content.

8. The instructor needs to step - in and actively facilitate the roleplays if students struggle while clearly conveying that students have the primary responsibility for enacting the role-play and actively participating in discussions.

9. It is important for students to observe groups in action. Therefore, course content should include a DVD and/or links to online videos; YouTube has many excellent videos of groups that are free of charge and can be linked into the course content. . The course syllabus should clearly state when the visual material should be viewed and integrate this content through discussion questions and assignments.

In conclusion, our technological age provides opportunities for teaching groupwork online and reaching students who might not otherwise be able to participate in this learning experience. In the prior discussion, the benefits and challenges of using an asynchronous format was explored. It is hoped this discussion will help stimulate interest in this topic as mental health services and education continue to evolve in online environments.

\section{References}

Association for Group Psychotherapy and Psychodrama. [Accessed 10 November 2012 at http://www.asgpp.org/ ]

Atherton, J. S. (2010) Learning and Teaching: Assimilation and Accommodation. [Accessed !5 November 2012 date at http://www.learningandteaching.info/ learning/assimacc.htm]

Bell, M. (2001) Online role-play: anonymity, engagement, and risk. Educational Media International, 38, 4, 251-260

Blatner, A. (2009) Role playing in education. [Accessed 30 October 2012 at 
Teaching groupwork at a distance using an asynchronous online role-play

http:www.blatner.com/adam/pdntbk/rlplayedu.htm]

Childress, M. D. and Braswell, R. (2006) Using massively multiplayer online role-playing games for online learning. Distance Education, 27, 2, 187-197

Coney, M.B. (2000) Role-playing on the web: Guidelines for designing and evaluating personas online. Technical Communication, 47, 3, 327-341

Crookwell, D, Oxford, R. and Saunders, D. (1987) Towards a reconceptualization of simulation: From representation to reality. Simulation Games for Learning. $17,4,147-171$

Jones, S. (2007) Adding value to online role-plays: Virtual situated learning environments. Proceedings Australasian Society for Computers in Tertiary Education Singapore, 468- 477 Accessed 22 April 2013 at http://www.ascilite. org.au/conferences/singapore07/procs/jones-s.pdf]

Joyner, B. and Young, L. (2006) Teaching medical students using role- play: Twelve tips for successful role plays. Medical Teacher, 28, 3, 225-229

Nelson, D. and Blenkin, C. (2007) The power of online role play-play simulations: Technology in nursing education. International Journal of Nursing Education Scholarship, 4, 1, 1-12

Parab, B. and Lewis, L. (2008) Distance Education at Degree-Granting Postsecondary Institutions: 2006-07. Washington, DC: National Center for Education Statistics, Institute for Education Sciences, U.S. Department of Education

Reinking, D, Labbo, L. and McKenna, M. (2002) From assimilation to accommodation: A developmental framework for integrating digital technologies into literacy research and instruction. Journal of Research in Reading, 23, 2, 110-122

Roschelle, J. (2010) Learning in Interactive Environments: Prior knowledge and new experience. [Accessed 23 October 2012 at http://www.exploratorium. edu/IFI/resources/museameducation/priorknowledge.html]

U.S. Department of Education, Office of Planning, Evaluation, and Policy Development (2009). Evaluation of Evidence-Based Practices in Online Learning: A meta-analysis and review of online learning studies. Washington, D.C.: Office of Planning, Evaluation, and Policy.

U.S. Department of Education, Institute of Education Sciences - National Center for Education Statistics (2011). Fast Facts: Distance education. [Accessed 11/5/12 at http://nces.ed.gov/fastfacts/display.asp?id=80]

Warburton, S. (2009) Second Life in higher education: Assessing the potential for and the barriers to deploying virtual worlds in learning and teaching. British Journal of Educational Technology, 40, 414-426

Yee, N. (2006) The Psychology of MMORGs: Emotional Investment, Motivations,

Groupwork Vol. 23(1), 2013, pp.56-72. DOI: 10.1921/1601230104 
Relationship Formations, and Problematic Usage. in R. Schroeder and A. Axelson (Eds.) Avatars at Work and Play: Collaboration and interaction in shared virtual environments. London: Springer Verlag (pp. 187-207) 